\title{
Habitar o Pós-Colonial: notas sobre trajetórias e pertenças entre pesquisadores indianos na Europa
}

\author{
Vinicius Kauê Ferreira \\ École des Hautes Études en Sciences Sociales, Paris, França \\ E-mail:vinikaue@gmail.com
}




\section{Resumo}

A partir de uma pesquisa etnográfica sobre acadêmicos indianos em ciências sociais que buscam construir uma carreira na Europa, propõe-se uma reflexão sobre os estudos póscoloniais como espaço privilegiado de significação de trajetórias e de sentimentos de pertença. Mais precisamente, baseado em interlocuções de pesquisa com cerca de 20 acadêmicos indianos encontrados no Reino Unido, sugerese que este campo de estudos é frequentemente apropriado por seus autores em movimentos de inscrição de si no interior de grandes narrativas históricas e imaginárias em torno das complexas circulações das quais esses sujeitos são parte constituinte. Para isso, recorre-se a uma articulação entre dados etnográficos (observação participante e entrevistas), análise de obras como práticas discursivas e controvérsias teóricas que, como se demonstra neste artigo, são o elemento central na compreensão da produção de sentimentos de pertença entre esses sujeitos, assim como na significação de suas próprias trajetórias. Desse modo, este artigo busca aportar elementos etnográficos para o debate sobre os estudos póscoloniais.

Palavras-chave: Pós-Colonial. Circulações Acadêmicas. Trajetórias. Índia. Europa.

\section{Abstract}

By drawing upon an ethnographical research on South Asian social scientists carving out an academic career in Europe, this article assesses the way how postcolonial studies may be seen as a privileged space of production of meanings regarding their trajectories and senses of belonging. More specifically, by exploring a series of interlocutions hold during my fieldwork in the United Kingdom, where I could interview about 20 scholars, I suggest that this field of studies is frequently appropriated by its authors as a way of inscribing themselves in great narratives and imaginaries involving the complex circulations of which they are constitutive part. To that end, I bring into play an articulation not only of ethnographical data (namely participant observation and interviews), the analysis of publications as discursive practices, and theoretical controversies that, as I argue in this article, are a central ethnographical element to understand the production of senses of belonging amongst these subjects, as well as in the way how they interpret their own trajectories. In sum, I seek to contribute to the debates on postcolonial studies from an ethnographic point of view.

Keywords: Postcolonial. Academic Circulations. Trajectories. India. Europe. 


\section{Habitar o Pós-Colonial}

Their new world had no room for the words that lived in their imagination. (Amitav Ghosh, The Diaspora in Indian Culture, p. 76)

Proponho aqui partir de minha pesquisa doutoral sobre pesquisadores indianos em ciências sociais que buscam construir uma carreira acadêmica na Europa para pensar a crítica pós-colonial como um espaço de produção de localidades ${ }^{1}$ e pertenças, por meio da produção de teoria ${ }^{2}$. Explorando narrativas colhidas durante trabalho etnográfico no Reino Unido entre 2015 e 2016, argumentarei que não apenas grande parte da literatura produzida por intelectuais que trabalham neste país, mas também suas trajetórias têm o efeito de lhes conferir um lugar no interior de grandes narrativas e conectá-los simbolicamente, por meio de narrativas e sentimentos pós-coloniais, a territórios e histórias precisas. Para tal, pretendo navegar também por debates teóricos, que revelam certa insistência na produção de narrativas centradas em deslocamentos e pertenças, mas desejo, sobretudo, trazer elementos etnográficos mais concretos, explorando notadamente marcadores sociais como casta, classe e origem que explicam de que modo a teoria pode ser um espaço de ressignificação de trajetórias, projetos e posições sociais.

Inscrevo-me assim numa antropologia pós-colonial do campo acadêmico, o que significa investir numa análise de dinâmicas e temas caros aos estudos pós-coloniais, desde uma perspectiva primariamente etnográfica. Portanto, mesmo textos são compreendidos aqui como práticas discursivas, elementos etnográficos, que são a expressão de sentimentos de pertença e que podem ser instrumentos de significação de seus percursos, muito mais do que objeto de exegese. Em certa 
medida, o movimento realizado neste artigo se inspira em trabalhos no campo da história da antropologia que buscaram entender obras e campos dentro de contextos históricos e intersubjetivos (Peirano, 1981), também desde um posto de vista feminista (Grossi, 2006) e desde uma perspectiva de ressignificação (Ribeiro et Escobar, 2006). Mas, acima de tudo, ela se constitui um movimento de inscrição de debates teóricos a uma etnografia multissituada dos espaços acadêmicos em sua dimensão multiescalar (Cesarino, 2014), globalizada (Ribeiro, 2014), pôs-colonial e disputada (Bourdieu, 1984).

As ideias desenvolvidas aqui são baseadas em minha pesquisa doutoral sobre cientistas sociais indianos que têm construído carreira acadêmica na Europa, especialmente no Reino Unido e na Alemanha. Uma de minhas questões de pesquisa, e que buscarei explorar neste artigo, tem sido compreender como esses sujeitos forjam relações de pertença, frequentemente múltiplas e complexas, ao longo de trajetórias marcadas por intensa circulação entre certos países. O objetivo central deste artigo, aquilo que pretende ser sua possível contribuição para o debate sobre os estudos pós-coloniais, é o de aportar elementos etnográficos na compreensão sobre a produção deste campo, acordando, para isso, muito mais espaço às narrativas e trajetórias do que aos debates estritamente teóricos ou às acusações de ordem moral que parecem dominar as páginas das publicações dedicadas a esta questão e que movimentam uma máquina que produz, a meu ver, muito mais calor do que luz.

Para tal, começarei por uma análise de narrativas colhidas durante meu trabalho de campo que restituem de modo representativo a articulação entre sentimentos de pertença e teoria. Buscarei mostrar como campos teóricos, tais como os estudos de área, os estudos pós-coloniais e a noção de diáspora funcionam como uma forma de significação, digamos epistemológica, de processos de construção de subjetividades que se pretendem cosmopolitas. Na segunda seção do artigo, articulo as narrativas a certa literatura pós-colonial a fim de demonstrar a centralidade atribuída por estes sujeitos, tanto na literatura quanto em minhas interlocuções, à noção de sua presença - e pertença - em determinados espaços. Demonstro que a noção de espaço 
adquire aqui um sentido amplo de modo a englobar experiências de deslocamento ao mesmo tempo geográfico, subjetivo e epistemológico. Em seguida, busco restituir brevemente as controvérsias teóricas e morais em torno do projeto pós-colonial e, sobretudo, de seus atores. Interessa-me aqui explorar os conflitos e tensões evocadas pelo modo como acadêmicos pós-coloniais construíram tal campo de significação de seu tempo e das circulações das quais eles mesmos fazem parte. Apesar de investir sobre o debate teórico, esta seção é fundamental para compreender - numa leitura a contrapelo - como este campo é produzido por marcadores sociais bastante específicos, tais como casta, classe e origem. Finalmente, encerro o artigo retornando a dados etnográficos que ilustram estas disputas e proponho algumas reflexões sobre o que significa uma perspectiva antropológica sobre a produção de teoria que não seja apenas uma leitura historicista ou exegética de obras.

Considerando que em minha pesquisa a relação entre interlocutores e referenciais teóricos é complexa, pois tenho estudado intelectuais que podem ser também meus referenciais teóricos, cabe sublinhar que os autores citados neste texto não são necessariamente meus interlocutores de pesquisa. Este esclarecimento faz-se necessário em razão da condição de anonimato das interlocuções estabelecidas. Afinal, não quero correr o risco de suspeitas inversas - ou seja, deixar espaço à ideia de que as pessoas que cito aqui são necessariamente meus interlocutores.

\section{Retornar à Ásia do Sul}

Um de meus interlocutores, que nomearei ficticiamente Sunil, foi forjado por percursos e conexões complexas entre o Reino Unido e a Índia. Nascido no Reino Unido logo após seus pais, ambos médicos, terem chegado da Índia por razões profissionais, ele partiria ainda criança para a Índia no contexto de retorno de sua família, onde ele moraria até o final de sua adolescência. De volta ao Reino Unido para seus estudos universitários, tomaria um percurso muito pouco usual para acadêmicos que se reconhecem como parte da diáspora indiana: dedicar-se-ia em seu mestrado e doutorado a estudar temas não 
centrados na Ásia do Sul. Quando da proposição de seu pós-doutorado, entretanto, ele decidiria dedicar-se a questões diretamente associadas à história da Ásia do Sul. Comentando essa decisão, ele diria:

Eis a razão, eu acho, de ter mudado de tema. Eu não penso que fosse consciente de minha parte naquele momento. Analisando hoje, vejo que foi o que aconteceu. Há essa ideia de que se você é um acadêmico de origem sul-asiática você deve, portanto, se interessar em South Asian studies, você deve, portanto, fazer postcolonial studies. E eu penso que eu subconscientemente resistia a isso. E eu ouvi outros acadêmicos sul-asiáticos contando essa mesma história. Há quase um sentimento de que eu deveria provar a mim mesmo e todo mundo que eu não precisava fazer South Asian studies somente porque eu sou sul-asiático. E tendo feito algo diferente daquilo que se esperava de mim, tendo provado que eu poderia pesquisar outras coisas, eu então me senti confortável para voltar à Ásia do Sul e fazer algo que era de fato pessoalmente relevante para mim.

Três são os elementos que eu gostaria de analisar de modo articulado: (a) sua autoidentificação como sul-asiático mesmo tendo nascido na Inglaterra; (b) considerar-se em diáspora e inscrever-se nos estudos pós-coloniais; e (c) sua alusão a voltar à Ásia do Sul ao decidir pesquisar aquela região.

Apesar de normalmente serem alcunhados de intelectuais diaspóricos, a grande maioria dos intelectuais indianos com quem pude conversar em diferentes lugares da Europa não se considera parte de qualquer diáspora. Isso porque a diáspora indiana é amplamente associada a identitarismos e a guetos culturais, ou ainda ao nacionalismo religioso hindu de extrema-direita crescente tanto no país quanto no seio da dita diáspora indiana ${ }^{3}$. Para eles, o essencialismo cultural e religioso hindu e o patriotismo conservador fomentado por comunidades diaspóricas seriam a antítese do cosmopolitismo que caracterizaria suas trajetórias e projetos. Entretanto, ao ver que alguns deles, que também se consideram cosmopolitas e contrários a tais lógicas de exclusão, como é o caso de Sunil, reivindicam subjetividades diaspóricas, faz-se necessário perguntar: onde se situa a fronteira entre aqueles intelectuais que se percebem como parte da diáspora e aqueles que 
buscam afastar-se dela? Parte da resposta, eu gostaria de sugerir, está no modo como sentimentos de pertença em relação à Índia são diferentemente tecidas e mantidas entre (a) aqueles que nasceram na Índia e depois migraram para a Europa para seus estudos superiores e (b) aqueles descendentes, que nasceram na Europa ou nos Estados Unidos e acabaram por construir laços com a Índia por meio da narrativa diaspórica e dos estudos pós-coloniais ${ }^{4}$.

Inicialmente, ao conceber uma pesquisa sobre intelectuais indianos, pensava em analisar narrativas de intelectuais nascidos na Índia e que haviam se mudado para a Europa, mas após escrever para alguns acadêmicos que, apesar de não terem nascido naquele país respondiam como intelectuais indianos, entendi a necessidade da superação de certo nacionalismo metodológico na pesquisa em ciências sociais. Reconhecer-se como um intelectual indiano não significa ter nascido na Índia ou portar um passaporte indiano - ainda que o passaporte seja um objeto central na produção de circulações e pertenças. Foi justamente o fato de incorporar à minha pesquisa interlocuções com pessoas nascidas na Inglaterra, nos Estados Unidos ou na África do Sul o que me permitiu compreender como a narrativa diaspórica e o debate pós-colonial podem se constituir elementos de produção de pertenças, mesmo que estes dois não sejam exclusivos àqueles intelectuais indianos nascidos fora da Índia. Como ele nos conta, é por meio da teoria, dos estudos pós-coloniais, que Sunil realiza seu projeto de voltar à Ásia do Sul mesmo que tendo nascido e morado a maior parte de sua vida no Reino Unido.

Contudo, poder-se-ia argumentar que os estudos pós-coloniais são majoritariamente - ao menos quando pensamos em seus representantes de maior projeção global - escritos por intelectuais nascidos nas antigas colônias, especialmente britânicas e francesas, que depois migraram para os centros, o que é diferente do que estou sustentando ao trazer a trajetória de Sunil. De fato, o pós-colonial, tanto em sua versão francófona - com autores fundadores como Franz Fanon e Aime Césaire - quanto em sua versão anglófona - com os autores subalternistas - ou ainda latino-americana - com autores que se converteriam em decoloniais, ou ainda que criticam estes últimos ${ }^{5}$ 
- vieram desses territórios colonizados. Não obstante, o elemento diferenciador da narrativa não apenas de Sunil, mas também de outros de meus interlocutores de famílias migrantes de segunda ou terceira geração, é a incorporação voluntária da noção de diáspora à construção de suas narrativas, e que não é necessariamente compartilhada por aqueles que se filiam aos estudos pós-coloniais, mas que nasceram e cresceram na Índia; trata-se, no caso de sujeitos como Sunil, de sujeitos pós-coloniais diaspóricos.

Essa constatação não é secundária, pois fala muito claramente sobre a centralidade da narrativa diaspórica na construção de sentimentos de pertença na distância e no deslocamento, por meio da qual localidades e pertenças não se equiparam a territórios ainda que continuem a precisar deles. Outro de meus interlocutores, que chamarei aqui de Irrfan, nascido e educado na Índia, tendo se mudado para o Reino Unido para seu doutorado, e inscrito no debate pós-colonial, ajuda-nos a entender melhor de que maneira a narrativa da diáspora é operada, dentro dos estudos pós-coloniais, como um signo conector com um território que se habita, sobretudo, simbolicamente. Quando perguntado sobre a importância da categoria diáspora para si, questionando-lhe se ele se consideraria um sujeito diaspórico, ele responderia: Eu não sinto como se fosse parte da diáspora. Eu parti muito tarde e volto com muita frequência.

Irrfan também fala da cidade na qual cresceu na Índia com grande familiaridade e certa nostalgia, o que é bastante comum entre intelectuais que reivindicam perspectivas pós, trans ou antinacionais. As metrópoles indianas, em muitas dessas narrativas, aparecem como espaços cosmopolitas por excelência: o local é cosmopolita porque conectado ao mundo, e é, portanto, produtor de pessoas cosmopolitas ${ }^{6}$. Nesse sentido, metrópoles como Mumbai, Delhi, Kolkata e Chennai seriam tropos de um cosmopolitismo vernacular, que não se restringe ao nacional ou ao nacionalismo que se busca negar. Elas seriam a localização do cosmopolita e de um movimento contemporâneo de crítica segundo o qual o nacional é, ao contrário, sinônimo de patriotismo essencialista e provinciano, avesso a certo cosmopolitismo global. Nesse contexto, parece haver uma retificação de cidades, que passam 
a ser vistas como o local de realização não apenas da modernidade, mas, sobretudo, de certa multiculturalidade que preenche de conteúdo a abstração do global cosmopolita. Aqui, também pequenas cidades podem ser tidas como cosmopolitas na medida em que aparecem como o palco de encontro de culturas locais diversas, mesmo se as grandes cidades, as ditas cidades globais, aparecem mais frequentemente como uma ponte entre o local e o global por serem uma espécie de espaço multicultural.

Assim como a maioria de meus interlocutores, Irrfan volta frequentemente à Índia, sobretudo à sua cidade natal, por volta de uma ou duas vezes ao ano, seja por razões de pesquisa ou familiares. Trata-se de uma vida baseada na Inglaterra, mas animada pela circulação constante entre esta e uma grande cidade da Ásia do Sul. Irrfan, assim como Sunil, não mora num bairro étnico, não se alinha à política hindutva ${ }^{7}$ tão comum entre a diáspora indiana e nutre um relacionamento com um parceiro britânico. Contudo, diferentemente de Sunil, que nasceu na Inglaterra, Irrfan não reivindica uma subjetividade diaspórica, apesar de também integrar o debate pós-colonial sobre pertenças e movimentos sociais e políticos. As narrativas de interlocutores como Sunil e Irrfan, quando colocadas em perspectiva, corroboram empiricamente uma noção de diáspora que me parece mais potente como ferramenta heurística em meio ao inchaço de tal categoria ${ }^{8}$. Felizmente, autores como Khachig Tölölyam (2005), editor da revista Diasporas, têm realizado contribuições importantes no sentido de restituir a força do assente e do local na compreensão do que diásporas realmente significam. Em meio a um momento em que esta categoria parece remeter, sobretudo, a dinâmicas que caracterizariam um mundo de circulações incessantes e sem fronteiras - e que apaga as condições concretas de tais circulações e suas barreiras -, Tölölyam lembra que a produção de sentimentos e comunidades diaspóricas está muito mais fundada no sedentarismo do que na circulação.

A diáspora, de acordo com Tölölyam, é uma reivindicação daqueles que instalados em terras distantes circulam, mas que alimentam narrativas sobre uma terra à qual pertencem muito mais por meio do simbólico e de certa materialidade que confere concretude à narrativa diaspórica (a circulação de bens, alimentos, filmes, matrimônios, 
dinheiro etc.). Para pesquisadores como Irrfan, indianos nascidos na Índia e que retornam frequentemente, a diáspora é um discurso vazio de sentido. Ao dizer que partiu muito tarde e que retorna com muita frequência, Irrfan nutre uma conexão com aquele lugar que não passa pelo imaginário diaspórico, que ele, como outros, associa desdenhosamente a bairros étnicos, à romantização da homeland, às discriminações baseadas na casta e à etnicização de pertenças. Isso não quer dizer, contudo, que a narrativa de Irrfan seja desencantada, teoricamente distanciada ou altamente racionalizada - o que quer que isso possa dizer. É verdade que meus interlocutores frequentemente buscam elaborar respostas que me mostrem alguma capacidade de reflexão autocrítica em relação a suas posições como sujeitos; contudo, mesmo intelectuais, por maior que sejam suas habilidades retóricas e de teorização, são ao fim das contas sujeitos submersos em códigos culturais ordinários. Por exemplo, como disse antes, a ligação que se nutre com as cidades de onde vêm são essencialmente romantizadas, o que é importante para fins de análise em um contexto cultural em que as metrópoles são vistas como espaços altamente cosmopolitas e modernos.

Mas há que se considerar também como classe produz tais aproximações ou distanciamentos com a narrativa da diáspora. Ou, como Sunil diria ao reivindicar sua identidade diaspórica, como a pertença de tais indivíduos a determinada classe social lhes permite não se considerar parte da diáspora. O que ele pretende com esta provocação é mostrar que sujeitos nascidos em famílias intelectualizadas de classes média e alta e de altas castas, como é a quase totalidade de meus interlocutores, e que sempre experienciaram o que se convém chamar atualmente de migração privilegiada como estudantes e acadêmicos (Croucher, 2012; Van Boekel, 2013), poderiam facilmente ignorar seus privilégios de classe que lhes permitiria não recorrer a reconstruções imaginadas de uma terra distante, ou não necessitariam das redes de solidariedade locais pelas quais as comunidades diaspóricas se constituem. Sua circulação intensa entre Inglaterra e Índia que, como mostrei acima, não dá espaço à diáspora como sentimento de profunda ligação a certa Índia, é viável devido à posição social e econômica que 
ocupam no circuito internacional. Classe aqui, portanto, não é pensada apenas em termos de renda, senão como capital simbólico e estilo de vida (Bourdieu; Saint-Martin, 1976) que configuram sujeitos não apenas com acesso a recursos materiais e simbólicos, mas também propensos à inscrição em narrativas que mobilizam termos como cosmopolitismo e cidadão global, vistos como opostos à uma espécie de etnicidade provinciana das narrativas diaspóricas.

Realizando um pequeno détour, vale à pena citar Homi Bhabha em seu prefácio à edição Routledge Classics de The Location of Culture, onde ele explicita tais questões:

Partir de Bombay nos anos 1970 para estudar Inglês em Oxford foi, de diferentes maneiras, a culminação de uma trajetória própria à classe média indiana, na qual educação formal e 'alta' cultura uniram-se ao emular os cânones do gosto 'inglês' de elite (ou o que conhecemos disto) e ao se conformarem aos seus hábitos e confortos. Minha vida quotidiana, entretanto, legou-me uma herança bastante diferente. Ela foi vivida naquela rica miscelânea cultural de línguas e estilos de vida que a maioria das cidades cosmopolitas indianas celebra e perpetua em sua existência vernacular - o hindustani de Bombay, o gujarati 'parse', o marathi crioulo, todos cultivados numa mistura de inglês com sotaque missionário galês temperado com dialeto anglo-indiano que era às vezes rejeitado por serem vistos como gírias americanas retiradas de filmes ou da música popular. (Bhabha, 2004 [1994], p. x)

Sunil, nascido na Inglaterra e que se reconhece na diáspora, não possui uma origem de classe diferente da maioria de quase todos os meus interlocutores, ou daquela de Bhabha; ele é filho de médicos liberais de classe média alta. Contudo, ele adota a narrativa diaspórica como uma posição ética ${ }^{9}$, uma sorte de inscrição em debates contemporâneos preocupados com o significado político das circulações e pertenças múltiplas produzidas por deslocamentos históricos e disjunções entre as diferentes esferas da vida, para recorrer novamente ao léxico appaduraiano (Appadurai, 2003). Ou seja, Sunil, junto com os estudos pós-coloniais, adota a diáspora como um espaço de pertença a circulações, narrativas, processos e mesmo um território. Irrfan, 
por sua vez, que nasceu na Índia, mesmo não subscrevendo qualquer identidade diaspórica, recorre ao debate pós-colonial para produzir narrativas que elaborem teoricamente seu lugar no mundo. Ambos publicam sobre temas diretamente relacionados a noções de pertença, mobilizações políticas e relações de poder, e estão engajados em reflexões que não apenas descrevem mundos, mas também cultivam paisagens habitáveis para si no seu interior.

\section{O Lugar de Reflexão e o Lugar como Reflexão: teoria e subjetividade}

Gostaria de aprofundar essas considerações etnográficas articulando-as com uma análise da obra supracitada de Homi Bhabha, O Local da Cultura, a fim de entender como posições, territórios e fronteiras constituem-se em objetos cruciais de reflexão para a literatura pós-colonial. O trecho citado anteriormente é bastante representativo de como a questão do deslocamento geográfico, social e cultural são profundamente constituintes da trajetória pessoal e teórica de Bhabha. Mas a espacialidade e a localidade da articulação subjetividade-teoria podem ser altamente alegóricas:

Às vezes, a língua inglesa tinha o toque arcaico de um tradicional armário entalhado que tragou você para o cheiro esmaecido de naftalina e belos e frágeis lençóis; outras vezes, tinha a força da combinação e da mistura características de uma festa popular, tal como a comida de rua temperada e barata de Bombay, disponível em todos os tipos de quantidade e combinação, deliciosas iguarias com o sabor do estilo de vida urbana. Eu fui para Oxford para refinar o charme do antigo armário; eu acabei percebendo o quanto eu desejava comida de rua. (Bhabha, 2004 [1994], p. x)

A alusão ao armário e à rua, ao cânone acadêmico e à vida urbana popular, parecem propositalmente misturar as esferas das trajetórias pessoal e acadêmica. Como já dito anteriormente, este trecho é retirado do prefácio que Bhabha escreve a uma edição publicada em 2004 do Local da Cultura. O tom do texto é, portanto, deliberadamente autobiográfico, como se pode esperar de um prefácio à obra. Assim, a 
fim de sustentar que tais sobreposições não se restringem a escritos de cunho especialmente autobiográfico, sugiro uma leitura do seguinte trecho de um capítulo do mesmo livro - ainda que muitos outros trechos pudessem ser selecionados:

A atividade negadora é, de fato, a intervenção do 'além' que estabelece uma fronteira: uma ponte, onde fazer-se presente tem início porque captura algo da estranha sensação de relocalização do lar e do mundo - o estranhamento como sentimento de jamais se sentir em casa [the unhomeliness] - que é a condição de iniciações extraterritoriais e transculturais. Sentir-se sem casa, nesta condição de estranhamento [unhomed], não significa ser um sem-lar [homeless], e sequer pode aquele que vive tal estranhamento, de não se sentir em casa [unhomely], ser facilmente acomodado naquela conhecida divisão da vida social entre as esferas pública e privada. O momento de estranhamento [unhomely] toma você furtivamente [stealthily], como se fosse sua própria sombra, e repentinamente você se encontra com Isabel Archer, de Henry James em The Protrait of a Lady, tomando as medidas de sua casa num estado de inimaginável terror. E é neste ponto que o mundo primeiro se comprime para Isabel e em seguida se expande enormemente. (Bhabha, 2004 [1994], p. 13, tradução nossa)

A profusão de termos de referência espacial e de situacionalidade, sejam mais concretos ou mais abstratos, produz um cenário quase vertiginoso que o leitor deve 'atravessar': além, fronteira, ponte, relocalização, lar, mundo, casa, extraterritoriais, transculturais, divisão, esferas, ser tomado ( seu corpo), sombra, residência, compressão e expansão. É preciso dizer ainda que a tradução do inglês para o português de tal trecho tem o efeito de minimização dessa obsessão pelo espacial, especialmente pelo sentimento de sentir-se em casa, pois Bhabha investe num rico jogo de sentidos com a palavra home. De origem germânica, segundo o Merriam-Webster Dictionnary, trata-se de uma palavra de difícil tradução para as línguas latinas, pois suas

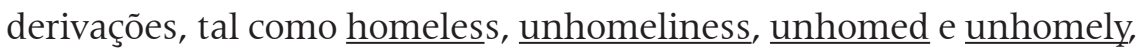
conduzem-nos à noção única de estranhamento como ausência de $\underline{\text { familiaridade com um local, que não apenas apaga a grafia do home }}$ 
[lar], mas ainda transforma em um só termo três variações empregadas para descrever o sentimento de jamais estar ou se sentir em casa. E a lista prossegue ao longo do livro: Terceiro Mundo, Terceiro Espaço (um conceito chave em sua obra), liminar, mundo da viagem, centro, margens e periferias ou ainda a ideia do Ocidente como um fórum cultural para o Terceiro Mundo (Bhabha, 2004 [1994], p. 31). E do mesmo modo que para meus interlocutores, geralmente vindos de famílias instruídas ou mesmo filhos de professores universitários, a vida acadêmica aparece como um espaço que pode cumprir o papel de home, ainda que uma casa possivelmente decorada pelos armários mofados dos quais fala Bhabha no trecho anterior.

Mas quando Bhabha nos fala sobre ser engolido pelo velho armário das grandes tradições, o que vem à tona é a questão da produção de sentido por meio de narrativas que são ao mesmo tempo acadêmicas e biográficas: como sujeito oriundo de famílias indianas de classe média, compartilhando de subjetividades altamente anglófonas (ou de supostas 'elites' anglófonas), Bhabha revela que elaborou seu lugar no mundo (acadêmico) por meio de narrativas intelectualizadas e que marginalizaram sentimentos e gostos populares, associados ao que ele chama de cosmopolitismo vernacular, tal qual a comida de rua, dos quais passou a sentir falta a partir de algum momento ${ }^{10}$. Tal processo é evidente entre meus interlocutores. Como já disse, parte deles articula representações de si baseadas em ideias como a do cidadão global ou cosmopolita, minimizando em suas narrativas espaços e práticas de pertença muito concretas que fazem parte de suas vidas, tais como a comida, a música ou mesmo os afetos e a conjugalidade, visto que muitos são casados com parceiros também indianos.

Em seus escritórios, locais em que normalmente conversávamos, encontrava com frequência referências a certa cultura intelectualizada indiana, tais como poemas de Rabindranath Tagore ${ }^{11}$, um busto do Mahatma Gandhi, fotos de intelectuais públicos do movimento de independência e mais raramente imagens religiosas. Assim como na narrativa de Bhabha, durante minhas conversas com estes pesquisadores, referências quotidianas tão importantes, como a comida na vida quotidiana, apenas eventualmente tinham lugar no modo como 
narravam e significavam suas trajetórias intelectuais. Em conversa com um de minhas interlocutoras, que chamarei aqui de Sharmila, que também escreve sobre temas como cultura popular na Índia, eu a provocaria dizendo que ao contrário das pessoas com quem eu havia conversado anteriormente, ela trazia memórias muito menos intelectualizadas. Enquanto outros frequentemente mencionavam Shakespeare e Satyajit Ray como repertório cultural de suas memórias, as referências desta interlocutora evocavam romances policiais populares, o que me chamou a atenção naquele momento. Sua resposta seria de que ela compreendia muito bem minha percepção, afinal, dizia ela, evocar tais repertórios culturais eruditos era o que se esperaria deles.

Não estou sugerindo que meus interlocutores buscassem diminuir a importância de tais signos e práticas mais prosaicas de modo deliberado, afinal, parece-me bastante claro que suas vidas quotidianas estão sim menos pautadas em tradições (alimentares, matrimoniais, musicais etc.) do que aquelas dos sujeitos diaspóricos de quem estes acadêmicos buscam afastar-se em suas narrativas. Para citar um exemplo, festividades como o Diwali ou Holi, que mobilizam enormemente as diásporas, não são necessariamente importantes para eles. O que proponho como hipótese de reflexão é o fato de que entre esses acadêmicos a teoria, notadamente a reflexão pós-colonial, ocupa o lugar de conexão, na esfera pública, a estes imaginários na medida em que ela se constitui em espaço possível de significação de suas próprias trajetórias e, mais do que isso, de construção de um lugar para si no interior de grandes narrativas nacionais e transnacionais, ao mesmo tempo em que criticam e reconstroem estas últimas. Com isso, quero dizer que eles mobilizam o quadro de reflexão pós-colonial para produzir complexas relações de pertença, de visibilidade e de prestígio para si dentro de esferas que são ao mesmo tempo locais e globais, íntimas e públicas, pessoais e acadêmicas.

Retomemos a fala de Sunil, nascido na Inglaterra e que decidiu voltar à Ásia do Sul em seu pós-doutorado. Um de seus argumentos é o de que ele decidira escolher um tema que lhe era de fato pessoalmente relevante, uma afirmação muito recorrente entre esses acadêmicos. Com efeito, este princípio pode ser facilmente encontrado nas trajetórias de 
muitos acadêmicos fora dos estudos pós-coloniais também. Atualmente pós-doutoranda na Alemanha, uma de minhas interlocutoras, que não inscreve suas pesquisas naquele campo, diz que o período de seu doutorado foi de grande satisfação pessoal, e quanto ao seu tema de pesquisa ela decidira que se eu iria passar quatro anos tão intensos, eu tinha que fazer algo que tivesse muito sentido para mim. De fato, o seu tema de pesquisa estava diretamente relacionado a experiências pessoais que, de acordo com ela, as incomodava muito durante sua juventude, num nível emocional. Evidentemente, o fato de que a escolha do tópico de pesquisa esteja pautada em trajetórias, interesses e experiências pessoais é um debate amplamente explorado nas ciências sociais, ao menos desde o século XIX com Max Weber (2006) - que já utilizava o termo objetividade entre aspas - até a longa história que possui esta reflexão no campo feminista (Haraway, 2005; Grossi, 1992). O que gostaria de enfatizar, contudo, é que no caso dos estudos pós-coloniais parece haver certa centralidade da reflexão sobre o deslocamento, ao mesmo tempo subjetiva e geográfica, que ocupa um papel fundamental no modo como experiências pessoais são significadas teoricamente e de como teorias são produzidas.

A força de tal articulação é sem dúvida potencializada na medida em que mobilidade se transforma num conceito chave para a literatura sobre a modernidade. Também no quadro das atuais políticas científicas internacionais, a mobilidade é frequentemente valorizada entre instituições e pesquisadores e, cada vez mais, apropriada como uma espécie de ativo que confere valor no mercado acadêmico global ao diploma expedido por instituições que se pretendem altamente internacionais. Por isso, o discurso em torno da mobilidade científica tem se tornado uma questão essencial desta pesquisa, visto que ser móvel não é um estilo de vida sem efeitos sobre a vida privada e mesmo acadêmica de pesquisadores contemporâneos, do mesmo modo que a estrutura acadêmica atualmente existente no plano internacional, cada vez mais arquitetada em torno da lógica da mobilidade, não existe num vácuo político, cultural e econômico. Não poderei entrar num debate mais detalhado sobre esta questão aqui, mas gostaria de mencionar esta esfera das trajetórias acadêmicas porque ela nos ajuda 
a entender o que representa (e como é representado) o deslocamento, num sentido bastante amplo do termo, para os sujeitos que vivem tal condição; seja em contextos coloniais ou pós-coloniais ${ }^{12}$.

Uma das obras mais profícuas quanto à produção de identidades na era das circulações pós-coloniais, e de suas mobilidades, é provavelmente a de Stuart Hall. Seus textos são uma divagação sensível e complexa sobre a questão das identidades e políticas culturais numa era em que, como diz Hall, somos todos, de certa maneira, recentemente imigrados. Afinal, essa marginalidade [identitária] tornada central é realmente a experiência pós-moderna por excelência (Hall, 2013, p. 20, tradução nossa). Nascido na Jamaica, então colônia inglesa, Hall é parte dos jovens estudantes que partiriam para estudar no centro do império, integrando circulações extremamente tradicionais nos contextos coloniais e pós-coloniais. Sua narrativa e reflexão teórica articulam as conexões geográficas, históricas, culturais e epistemológicas entre diferentes partes destes sistemas coloniais, a fim de mergulhar nas ambiguidades inerentes à subjetividade pós-colonial (noção esta tão cara ao debate pós-colonial dos anos 1990).

Primeiramente, enfatiza Hall (2013), a condição colonial forjaria sujeitos para os quais a noção de deslocamento representa um descritivo de processos profundamente constitutivos de suas subjetividades num sentido muito amplo, para além dos deslocamentos geográficos:

Se você vive, como era meu caso, na Jamaica, numa família de classe média baixa que fazia tudo para ser uma família jamaicana de classe média, que fazia tudo para ser uma família jamaicana de classe média alta, que fazia tudo para ser uma família da Inglaterra vitoriana, a noção de deslocamento como lugar de identidade é um conceito com o qual você aprende a viver antes mesmo de saber soletrá-lo corretamente. (Hall, 2013, p. 21, tradução nossa)

E para complexificar a reflexão sobre a produção de identidades e localidades, a própria ideia de partida torna-se um processo nada simples a descrever: gente como eu, que veio para a Inglaterra nos anos 1950, sempre esteve lá por séculos; simbolicamente, nós estivemos lá por séculos. Eu estava voltando para casa. (Hall, 1997, p. 48, tradução nossa). Há aqui uma sobreposição entre espaços e pertenças: Hall 
sempre esteve na Inglaterra, sempre habitou aquele território, o que fazia de sua partida um retorno simbólico para casa. Sua trajetória é definida por um deslocamento que é altamente englobante, pois é ao mesmo tempo social, cultural e, acima de tudo, definidor de sua constituição como sujeito. Para Hall, nos tempos atuais, em que as margens passam a ocupar os centros ( seja por meio das diásporas, seja por meio de movimentos populares como as manifestações de jovens negros no centro de Londres), tornamo-nos todos imigrantes; mesmo aqueles que jamais migraram. Não há refúgio possível da experiência do deslocamento, que caracterizaria ao duplo pós-colonialidade/pósmodernidade. O sujeito contemporâneo é, portanto, uma espécie de bricoleur lévi-straussiano pós-moderno, um artesão que não lida mais com o material cultural local, bruto, mas sim com objetos e parafernalhas que chegam de todo canto e das quais é preciso construir algo que apenas dificilmente será o armário com cheiro de naftalina no qual Bhabha ver-se-ia engolido. E se para Bhabha esta fragmentaridade desconfortante é o que nos resta - expressando certo conformismo voluntarioso -, já para Hall esta aura migrante que caracteriza nosso tempo parece se apresentar como uma chance criativa - ainda que pouco óbvia.

Quando questionado sobre o fato de praticamente todos os intelectuais indianos na Europa trabalharem sobre a Índia, um de meus interlocutores buscaria alargar o escopo desta consideração. Ele argumentaria que se, por um lado, a constatação é verdadeira, por outro lado é preciso levar em conta que cada vez mais acadêmicos indianos têm se interessado por conexões envolvendo outras regiões do globo, mesmo que em relação com a Índia. Para ele, tratar-seia de um resultado da maior e mais diversa circulação vivida pelos pesquisadores indianos, que por consequência passariam a se debruçar sobre circulações transnacionais como são as suas próprias. Mais do que isso, tais circulações seriam frequentemente pensadas em termos de relações de poder, de geopolíticas, e mesmo de subalternidade, como são aquelas vividas por eles. Em vista disso, a relação entre um lugar no universo supostamente móvel da academia internacional supostamente porque mesmo tal mobilidade poderia ser relativizada ao 
analisarmos entre quais instituições e em que termos tais circulações internacionais acontecem - e uma teoria que dê conta de elaborar tais trajetórias parece encontrar bom refúgio na reflexão pós-colonial.

De fato, a ideia de que os pesquisadores indianos são altamente móveis, o que é valorizado entre instituições internacionais, é bastante compartilhada entre chefes de departamento com quem pude conversar em diferentes instituições da Europa que têm contratado um número significativo de professores indianos. Esse aspecto de trajetórias acadêmicas, qualificado no campo acadêmico anglófono como exposure, é vista como um atributo que confere grande vantagem a meus interlocutores. E, pelo que pude perceber, muitos têm consciência disso, enfatizando não apenas que migrações e deslocamentos são dinâmicos, comuns e constituintes da sociedade indiana, mas que a diversidade cultural e linguística do país produz aquele cosmopolitismo vernacular do qual nos fala Bhabha: segundo esse argumento, mover-se entre suas regiões é equivalente a circular entre diferentes culturas. Logo, se juntarmos a este fato - que, é preciso dizer, é confirmado pelas suas trajetórias familiares - a condição da qual nos fala Hall sobre sujeitos em mobilidade social e subjetiva na relação com o centro intelectual que é a Inglaterra, o resultado é o de sujeitos forjados no cruzamento de narrativas, práticas e valores altamente complexos.

\section{Autobiografia e Metanarrativa}

Mas se os estudos pós-coloniais permitem a sujeitos constituídos no cruzamento de processos históricos altamente complexos de elaborar teoricamente tais superposições, é preciso ter em mente uma dimensão fundamental deste exercício: o fato de fazê-lo desde a Europa. O espaço cavado por meio do pós-colonial não é apenas simbólico, ele tem também sua expressão concreta no mundo acadêmico anglófono europeu e estadunidense. Não à toa, a crítica pós-colonial vem frequentemente acompanhada da crítica aos fundamentos do que é a própria teoria no dito Ocidente ao mesmo tempo em que se apropria e se alimenta dela. Ou, como diria um de seus críticos, [a]gora é irônico, para dizer o mínimo, que o signo do rompimento com a teoria Ocidental é mostrar grande proficiência nela (Kaviraj, 2003, p. 161). Não é por acaso que 
se, por um lado, o pensamento pós-colonial como campo de estudos consolidou-se por meio da crítica à natureza do conhecimento dito ocidental, por outro, como provoca Suditpa Kaviraj, é ao menos irônico de supor que demonstrar um grande domínio da teoria ocidental seria o sinal de sua superação (Kaviraj, 2000, p. 84). Afinal de contas, construir-se um lugar no seio da academia europeia - ou estadunidense - é o projeto destes pesquisadores. Por isso, nas próximas páginas, eu gostaria de explorar algumas controvérsias que seguem no sentido da afirmação de Kaviraj, sempre me interessando na questão do póscolonial como espaço de significação e de reflexão etnográfica sobre essas trajetórias.

Retornemos às narrativas de Stuart Hall sobre a condição do sujeito pós-colonial de classes médias que migra para a metrópole. Em seus textos, aquele é um sujeito que sempre habitou o centro, que sempre esteve lá desde séculos, nas mais diversas formas:

Eu sou o açúcar no pires do aparelho de chá britânicos. Eu sou essa paixão pelos doces, eu sou essas plantações de açúcar que estragaram os dentes de gerações de pequenos ingleses. E, por trás de mim, vocês sabem, há outras centenas de pessoas que são a própria xícara. (Hall, 2013, p. 61, tradução nossa)

A localidade aqui se metamorfoseia num tropo que conecta simbolicamente metrópole e colônias, que situa sujeitos na posição de objetos historicamente manuseados e degustados; sujeitos que ocupam um lugar nesta história de circulações da qual apenas muito dificilmente se se pode desvencilhar. Hall também nos fala da condição de sem lar do imigrante que, como citei acima: sabe que não retornará jamais para casa. A migração é uma viagem sem retorno. Não há 'casa' para onde retornar. Nunca houve. A questão que se coloca aqui, a partir também das passagens de Bhabha, é: em que medida tais teorizações podem ser representativas de dinâmicas globais, muito mais do que narrativas fundadas em trajetórias pessoais específicas? Se, como argumento neste artigo, a teoria é também um espaço de construção de um lugar para si no interior de narrativas nacionais e transnacionais, de que modo são elas mobilizadas neste processo? E a partir de qual 
posição de fala, em termos, por exemplo, de marcadores sociais, tais lugares são cavados no interior dessas narrativas?

As críticas visando os teóricos pós-coloniais constituem uma vasta literatura, apostando frequentemente em argumentos muito ácidos ou mesmo de cunho pessoal ${ }^{13}$. De algum modo, esses debates corroboram o que venho argumentando aqui, na medida em que o que parece estar em jogo, de modo muito peculiar aos estudos pós-coloniais, é justamente a localidade de fala desses sujeitos, ou o questionamento dos lugares ocupados por tais sujeitos tanto na academia europeia/ estadunidense quanto nas narrativas que reivindicam para si. De um lado, o jogo com a ambiguidade que envolve a legitimidade de suas falas e, de outro lado, a tentativa de desqualificação de seus trabalhos no campo acadêmico mais amplo. Ou seja, tais sujeitos pós-coloniais são acusados de jogarem deliberadamente com narrativas em torno de suas supostas posições subalternas, enquanto seriam eles sujeitos privilegiados em suas origens (de famílias abastadas e intelectualizadas, historicamente beneficiadas pelo colonialismo) usando a crítica ao pensamento ocidental como mote para cavar posições nos centros da academia ocidental. Também nesta controvérsia, encontramos uma profusão de metáforas envolvendo circulação e posições, frequentemente ambíguas:

[...] uma tentação elitista de construir para si um nicho transdisciplinar no sistema acadêmico anglófono (Ahmad, 1995; Robbins, 1993, chap. 5 e 6); uma burguesia compradora de estilo e formação ocidentais, de um grupo de intelectuais que faz a mediação no comércio das mercadorias culturais do capitalismo mundial para a periferia (Appiah, 1992; p. 149); uma legitimação de pensadores globalizados no teatro universitário da globalização (Friedman, 1999, e infra, p. 187-206) [...]. (Assayag; Bénéï, 2013, p. 18, tradução nossa)

O que é interessante aqui é como a constituição do campo dos estudos pós-coloniais parece girar em torno da questão da pertença e da localidade de seus teóricos no campo acadêmico e nas narrativas com as quais lidam, muito mais do que em qualquer outro campo de estudos. Mesmo o debate feminista, talvez o principal campo de 
discussão sobre a problemática da localidade da fala do pesquisador, pauta esta discussão numa relação muito orgânica com pesquisas empíricas, debates epistemológicos e movimentos sociais que superam a individualidade do récit de soi que domina a literatura pós-colonial. Mas o que me interessa como questão antropológica aqui certamente não é subscrever ou contestar as críticas de tom moralizante que cito acima, senão entender o que está em jogo nestas disputas por posições de fala e legitimidade.

Em artigo intitulado Brahmanism, Liberalism and PostColonial Theory [Bramanismo, Liberalismo e Teoria Pós-colonial], Ajay Gudavarthy argumenta que o que ele chama de Teoria Póscolonial - o uso do termo teoria aqui é ao menos controverso em razão da reconhecida fragmentaridade do campo - alinha-se com o bramanismo e o liberalismo em sua tendência ao centrismo teórico e político. Tratar-se-ia, argumenta ele, de uma espécie de politica da acomodação (Gudavarthy, 2016, p. 15), de aspecto quase conservador e contrarrevolucionário. Nesse quadro, a posição possível, negociada, que teóricos como Bhabha qualificariam como híbrida, ou de um Terceiro Espaço, e que carregariam em si uma potência transformadora a partir do e usando as ferramentas dos centros, seriam acusadas de serem excessivamente centristas e política e teoricamente vazias. Elas seriam a expressão da natureza eminentemente acomodatória das elites indianas que, historicamente, teriam se apropriado de narrativas subalternas na construção de uma subalternidade global que permite que a categoria de um 'subalterno' se torne vaga o suficiente para incluir um Dalit de uma comunidade marginalizada e um professor locado num Departamento de Estudos da Ásia do Sul de uma universidade nos Estados Unidos (Gudavarthy, 2016).

Rahul Rao, ao explorar alguns dos debates fundadores dos estudos pós-coloniais, também se debruça sobre tais questões - que parecem ser cada vez mais uma das questões centrais deste campo, tanto para aqueles que se inscrevem nele quanto para aqueles que o refutam. Rao lembra que muitos acadêmicos são avessos aos estudos pós-coloniais, e, sobretudo, aos estudos subalternistas, pelo apagamento que estes operam da classe como categoria de análise. Para estes, a emergência da 
crítica pós-colonial atenderia a uma necessidade do capitalismo tardio, mais transnacionalizado e flexível, que passaria a ser interpretado, desde este novo ponto de vista, pelo apagamento da classe e por meio de categorias vazias como hibridismo e cosmopolitismo.

Não coincidentemente, pós-colonialismo na academia é articulado pelos beneficiários desta forma de capitalismo - migrantes socialmente ascendentes oriundos das altas burguesias das antigas colônias migrando para as metrópoles e buscando empregos em seus setores profissionais (inclusive universidades). A alegação aqui é dupla. Ao produzir uma ideologia que minimiza classe em prol de outros marcadores de 'subalternidade', os provedores do pós-colonialismo outorgam a si mesmos um estatuto privilegiado na academia como representantes daqueles que são privados de direitos. (Rao, 2013, p. 14, tradução nossa)

Ou seja, a construção de tais narrativas, por meio das quais esses intelectuais se situam histórica e profissionalmente, e especialmente no que tange à produção subalternista, seria um trabalho de relocalização destes indivíduos em novos circuitos e historiografias por meio do apagamento do lugar privilegiado ocupado por eles em suas próprias sociedades. O discurso sobre a ambiguidade retorna aqui como um fantasma que ao mesmo tempo assombra indivíduos construídos no encontro colonial e funciona como um mediador útil entre o mundo da periferia e do centro. Logo, a ambiguidade não seria apenas um conceito central por possibilitar um quadro teórico de análise de nossa época e seus sujeitos, como reiteradamente sustenta Bhabha, mas também pelo fato de permitir a acadêmicos como Bhabha e Spivak, como esta última reconhece, de serem representantes do colonialismo interno burguês na Índia e da periferia nos Estados Unidos (Spivak, 1989). Nesse sentido, não apenas o apagamento da classe e da casta, mas também a centralidade da noção de ambiguidade parece ser uma estratégia conceitual fundamental dos estudos subalternos - e é preciso deixar claro que aqui falamos especialmente dos estudos subalternos, não dos estudos pós-coloniais como um todo - na edificação de lugares privilegiados no circuito acadêmico internacional e, ao mesmo tempo, 
de um lugar de figuras de resistência nesta história altamente conectada entre a Índia a o Atlântico Norte. Eis o que permitiria navegar entre um engajamento com a teoria, para citar Bhabha, e se opor sem desafiar, para citar Gudavarthy.

Ainda no que tange ao modo como o pós-colonial constrói paisagens habitáveis aos seus teóricos, Rao avança nas críticas ao trazer o que Arif Dirlik chama de solipsismo epistemológico: a projeção de suas subjetividades em suas leituras da condição global, o que faz com que suas próprias experiências de migração, exílio, liminaridade e pertença múltipla possam ser tratadas como representativas (Dirlik, 1997, p. 339). Rao termina por dizer ainda que, expressando incredulidade quanto à metanarrativas, eles na verdade terminaram elevando autobiografia ao estatuto de metanarrativa (Rao, 2013, p. 12).

Um último ponto que eu gostaria de sublinhar relativo a tais críticas, antes de retornar a meus dados etnográficos, é o que Gudavarthy chama de folclorização/etnização de grupos englobados pelo termo subalternos. Para ele, se o propósito anunciado pelos subalternistas de conferir dignidade às expressões culturais e religiosas dos ditos subalternos parece válido, ao fazer abstração de relações de poder e acessos a recursos que constrangem sua agência e seu modo de ação política, o efeito seria de etnização do subalterno em oposição ao moderno. Assim, ver-se-ia uma postura paternalista que celebra a força de expressões culturais populares sem, contudo, interrogálas criticamente. Nesse panorama, a ideia de comunidade, continua Gudavarthy, emergiria como uma imaginação sem a devida compreensão sociológica, uma categoria vazia que teria como único mérito produzir "Outro" da modernidade. Teóricos pós-coloniais têm mantido esta 'fantasia' mesmo que tenham ao mesmo tempo se tornado cada vez mais críticos de utopias da esquerda e sua variante marxista (Gudavarthy, 2016, p. 17, tradução nossa).

Em suma, todas estas críticas apontam para uma compreensão do pós-colonial, e especialmente dos subalternistas, como um espaço de produção de teorias sobre processos globais que não passariam de metanarrativas informadas por trajetórias específicas de sujeitos historicamente privilegiados. Mais do que isso, eles buscariam produzir 
um lugar para si tanto no circuito acadêmico internacional quanto em grandes narrativas históricas por meio da instrumentalização de Outros (subalternos) em posições antimodernas denunciadas por críticos como uma fantasia ou acomodatórias. O que fica claro em meio a estas controvérsias é que o pós-colonial é sem dúvida um espaço de produção disputada de localidades e de pertença por meio da teoria; seja por parte dos seus teóricos, seja por parte de seus críticos, que ao se engajarem em tais embates buscam traçar e derrubar, mesmo que de fora, fronteiras e edifícios que têm sido erguidos nesta paisagem acidentada que é o pós-colonial.

\section{De Volta à Etnografia}

Alguns de meus interlocutores se identificam em grande medida com as críticas mencionadas acima. Um deles, nascido na Inglaterra e que trabalha atualmente na Alemanha, mas que mantem um trânsito intenso entre a Europa e a Ásia do Sul, diria a respeito do que ele classifica de acadêmicos diaspóricos, asiáticos e negros instalados na Europa trabalhando sobre o Sul desde uma perspectiva pós-colonial:

Se você fala sobre o que se passa lá [no Paquistão] sem levar em conta relações de poder, se você usa isto de modo a gerar tensões aqui e distrair as pessoas do que está acontecendo lá, que é também o que muito intelectuais asiáticos e negros fazem, eu acho, inclusive aqueles de esquerda, então diáspora é um termo associado a privilégio, mesmo à exploração. Eu trabalhei no Paquistão, por anos, então eu vi como isso funciona e eu sei o que significa trabalhar lá, estar preso lá, e ver o que acontece aqui quando na verdade essas pessoas dizem que sabem o que está acontecendo lá, se aproveitando da gente de lá. Enfim, é muito perturbador.

[...]

De diferentes maneiras, círculos intelectuais, teoria pós-colonial, que é realmente importante para eles... e eles usam o tempo todo uma linguagem que causa impacto, certo? Descolonizar isso e aquilo, esse tipo de coisa. A indústria de relações raciais vai muito bem na Inglaterra porque você tem muitas oportunidades se faz isso, porque você pode extrair todo tipo de benefícios 
bastante lucrativos disso. Empregos, cara, você sabe... e financiamento de pesquisa, se você posa como radical.

Binoy é um dos pesquisadores que encontrei que se considera em diáspora, mas não subscreve à corrente pós-colonial, como fica claro acima. Ainda que especialmente interessado no tema das políticas culturais, considera-se um marxista que refuta as politicas de identidade tão presentes na academia britânica pela qual passou. Nesse sentido, ele integra as fileiras de acadêmicos marxistas que se opõem ao póscolonial, como é o caso também do supracitado Ajay Gudavarthy e outros ${ }^{14}$. Mas Binoy, além de se colocar de acordo com o tipo de crítica relevada por Gudavarthy, menciona o pós-colonial como uma estratégia de produção de trajetórias de prestígio no interior da academia europeia e estadunidense. Ele expõe assim a articulação entre produção teórica e trajetórias ou, mais precisamente, como, aos olhos de muitos pesquisadores, o pós-colonial é um campo que acomoda representações e trajetórias fundadas em privilégios, distanciamento desengajado e estratégias pessoais.

Mas ao antropólogo atento resta a questão: como transformar tais disputas em material de reflexão antropológica sobre a produção de subjetividades e sentimentos de pertença? E como evitar incorrer em moralismos e não se engajar desavisadamente nos não ditos e posições que resultam de redes pessoais e subjetividades que informam cada um dos múltiplos lados de tal campo?

Primeiramente, é preciso dizer que ao trazê-los não pretendo subscrevê-los, senão coloca-los em perspectiva com outras dimensões constituintes do trabalho acadêmico, desde um ponto de vista de uma antropologia da vida acadêmica. Trata-se, é verdade, em parte, de um procedimento analítico movido por certa inspiração bourdieusiana, mais sociológica, interessado na compreensão de estruturas e práticas nas disputas por construção de lugares de prestígio no campo (Bourdieu, 1984). Contudo, trata-se principalmente de um movimento que busca contextualizar uma análise que se pretende, sobretudo, antropológica, etnográfica, sobre a construção de campos e vidas acadêmicas por meio da análise de práticas quotidianas e narrativas, de trajetórias e projetos (Velho, 1981). Mais do que uma exegese, ou uma análise 
da obra destes pesquisadores e das controvérsias evocadas, cabe aqui entender como a prática da escrita é mobilizada, complementarmente, como agenciamento de imaginários e representações de si próprio e de Outros. Assim sendo, no contexto de uma pesquisa sobre acadêmicos diretamente implicados nestas controvérsias, a teoria pode, mais do que cumprir uma função heurística diante de uma problemática, tornar-se ela própria o objeto de análise etnográfica que deve ser colocado em perspectiva com outras práticas discursivas caras à etnografia, como tentei demonstrar aqui.

Essas práticas às quais me refiro dizem respeito à uma dimensão propriamente etnográfica, no sentido mais tradicional do termo, tal qual sociabilidades acadêmicas (tanto formais quanto informais: a vida quotidiana de laboratórios de pesquisa, debates, festas, relações de amizade, viagens etc.), mas também referentes à esfera da vida privada; sobretudo na medida em que ambos se sobrepõem. As narrativas de Sunil, Irrfan e Binoy nos falam de vidas construídas em meio a circulações de pessoas e ideias que não se realizam num vazio institucional, político ou de relações pessoais que forjam as redes acadêmicas e sociais nos quais estão inseridos ou desejam se inserir. Inscrever-se na reflexão pós-colonial, engajar-se em seus debates e controvérsias, releva de movimentos ao mesmo tempo teóricos e subjetivos que mobilizam de modo crítico e bastante refletido discursos que podem ser ativados contextual e estrategicamente. Pude verificar isso ao assistir palestras de um mesmo pesquisador indiano na Europa e na Índia, experiência que me ajudou a entender como estes acadêmicos podem transitar entre diferentes estratégias de comunicação, num jogo de afinidades que mobiliza representações de si e teoria de modo diverso diante de diferentes públicos.

\section{Notas}

1 Parto de um uso crítico da noção de localidade proposta por Arjun Appadurai, a saber: Vejo localidade como primariamente relacional e contextual, mais do que escalar ou espacial. Como uma qualidade fenomenológica complexa, constituída por uma série de conexões entre o sentido de imediatismo social, as tecnologias de interatividade, e a relatividade de contextos. (Appadurai, 1996, p. 178, tradução nossa). Falo de um uso crítico do termo porque se, por um lado, a abordagem de Appadurai permite conceber localidades menos territorializadas, por outro, ela 
parece exagerar a realidade de tal desterritorialização. Retornarei a este ponto mais à frente.

2 Toda vez que eu empregar o termo teoria, refiro-me à definição proposta por Raewyn Connell (2012, p. 9): Eu proponho uma definição algo ortodoxa. Teoria é o trabalho que o centro faz. A afirmação de Connell é evidentemente provocativa, portanto uma crítica à tradicional divisão entre reflexão teórica, realizada por países do Norte, e coleta de dados, realizada pelos países do Sul, que funda historicamente as trocas acadêmicas globais.

3 Para uma ampla análise da relação histórica entre nacionalismo e religião na Ásia e na Europa, ver van der Veer e Lehmann (1999).

4 Para uma resposta mais precisa e complexa à questão que coloco, seria necessário explorar também a relação entre construir uma carreira acadêmica em países europeus e fazê-lo nos Estados Unidos. Neste último, o discurso das políticas de identidade possui muito mais força na organização do sistema acadêmico (Bénéï, 2000 ) e confere acesso a muito mais recursos simbólicos e mesmo financeiros. Sanjay Subrahmanyam, historiador indiano trabalhando nos Estados Unidos e na França, relata que numa reunião com dois abastados cidadãos de origem indiana vivendo em Los Angeles interessados em financiar um centro de estudos sobre a Ásia do Sul, o historiador em questão teria ouvido que ele não poderia ser o diretor do centro, pois não era suficientemente indiano (Subrahmanyam, 2015, p. 14, tradução nossa). Subrahmanyam é um ferrenho crítico do que chama de políticas étnicas ligadas à mentalidade de gueto fomentada por inúmeros intelectuais indianos nas universidades estadunidenses (Subrahmanyam, 2015, p. 350, tradução nossa). As universidades inglesa, alemã e, especialmente, francesa, entre outras da Europa parecem ser menos receptivas a tais lógicas, e, portanto, menos porosas às narrativas diaspóricas entre seus estudantes e pesquisadores, apesar de elas existirem em alguma medida, especialmente no Reino Unido. Ramachandra Guha diz de modo bastante crítico: pois mudanças demográficas na academia americana e a emergência das 'políticas de identidade' conseguiram marginalizar os acadêmicos brancos da Ásia do Sul (Guha, 2003, p. 174).

5 Para este debate, ver Castro-Gómez e Mendieta (1998).

6 Sanjay Srivastava (1996) tece uma interessante análise sobre as noções de cosmopolitismo e modernidade envolvendo as cidades indianas.

7 Hindutva refere-se a um movimento político nacionalista de cunho religioso hindu, em franco crescimento na Índia. Ver uma análise destes movimentos, ver Bacchetta (1994; 2005).

8 Para uma crítica à multiplicação de sentidos atribuídos à categoria diáspora, ver Brubaker (2005).

9 Para a noção de subjetividade diaspórica como posição ética, ver Anand (2009).

${ }^{10}$ Impossível não se lembrar de Pierre Bourdieu, no documentário A Sociologia é um Esporte de Combate, de Pierre Carles, quando diz: quando se vem de um meio humilde e de uma região dominada, forçosamente tem-se vergonha cultural. Tinha vergonha do meu sotaque, eu queria corrigi-lo. Passei pela École Normale, etc. Quando eu retornava à minha região natal e ouvia o sotaque, aquilo me horrorizava. Ainda hoje escuto certos sotaques na rádio que me horrorizam fisicamente. Mesmo se este era o meu sotaque. Recentemente, ouvia Tillinac na rádio, que é um escritor alinhado à Chirac, que fala com o sotaque de Brive. Eu sinto vontade de matá-lo. Isso me horroriza. Não somente pelo que ele diz... bom, isso é uma forma de violência simbólica. 
11 Grande literato bengali indiano da início do século XX. Para uma visão exploratória de sua obra, ver o volume II de seu Omnibus, publicado em 2003.

12 Em outro artigo (Ferreira, 2017), realizo uma análise mais demorada da noção de mobilidade e sua relação com outras dimensões da vida quotidiana. Articulando uma antropologia da globalização e reflexões avançadas pela antropologia das emoções, interesso-me pela relação entre mobilidade e precarização do trabalho e da vida acadêmica.

13 Para uma lista não exaustiva de tais críticas, ver Assayag e Bénéï (2003, introdução). Para obras críticas, ver Chibber (2013) e Shankar (2012). Ver também Appadurai (2003) e Spivak $(1992 ; 2014)$ para comentários dos próprios teóricos.

${ }^{14}$ Um exemplo bastante representativo e elucidativo dos desentendimentos entre marxistas e pós-coloniais é o debate recente em torno do livro publicado por Vivek Chibber, Postcolonial Theory and the Specter of Capital. Gayatri Spivak publicou uma resposta ao argumento do livro, essencialmente centrado sobre os estudos subalternos (2014), em seguida replicada por Chibber (2014).

\section{Referências}

ANAND, Dibyesh. Diasporic subjectivity as an ethical position. South Asian Diaspora, [S.l.], v. 1, n. 2, p. 103-111, 2009.

APPADURAI, Arjun. Knowledge, circulation and collective biography. In: ASSAYAG, Jackie; BÉNÉÏ, Véronique (Org.). At home in diaspora:

South Asian scholars and the West. Bloomington: Indiana University Press, 2003. p. 28-43.

ASSAYAG, Jackie; BÉNÉÏ, Véronique (Org.). At home in diaspora: South Asian scholars and the West. New Delhi: Permanent Black, Indiana University Press, 2004.

BACCHETA, Paola. All our goddesses are armed: religion, resistance and revenge in the life of a militant hindu nationalist woman. In: BHASIN, Kamla; KHAN, Nighat; MENON, Ritu (Org.). Against all odds: essays on women, religion and development from India and Pakistan. New Delhi: Kali for Women, 1994. p. 133-156.

BACCHETTA, Paola. Hindu nationalist women as ideologues. In: JAFFRELOT, Christophe (Org.). The Sangh Parivar: A Reader. New Delhi: Oxford University Press, 2005. p. 108-147.

BAYLY, Susan. Caste, society and politics in India. Cambridge: Cambridge University Press, 2010.

BÉNÉÏ, Véronique. Nations, diaspora et area studies: l'Asie du Sud, de la Grande-Bretagne aux États-Unis. L'Homme, [S.l.], n. 156, p. 131-160, 2000.

BHABHA, Homi. The location of culture. London and New York: Routledge, 2004 [1994]. 
BOURDIEU, Pierre. Homo Academicus. Paris: Les Editions de Minuit, 1984.

BOURDIEU, Pierre; SAINT-MARTIN, Monique. Anatomie du gout. Actes de la Recherche en Sciences Sociales, [S.l.], v. 2, n. 5, p. 2-81, 1976.

BRUBAKER, Rogers. The 'Diaspora' Diaspora. Ethnic and Racial Studies, [S.l.], v. 28, n.1, p. 1-19, 2005.

CASTRO-GÓMEZ, Santiago; MENDIETA, Eduardo (Org.). Teorías sin disciplina: latinoamericanismo, poscolonialidad y globalización en debate. México: Miguel Ángel Porrúa, 1998.

CESARINO, Leticia. Antropologia multissituada e a questão da escala: reflexões com base no estudo da cooperação Sul-Sul brasileira. Horizontes Antropológicos, [S.l.], v. 20, n. 41, p. 19-50, 2014.

CHIBBER, Vivek. Making sense of postcolonial theory: a response to Gayatri Chakravorty Spivak. Cambridge Review of International Affairs, [S.l.], v. 27, n. 3, p. 617-624, 2014.

CHIBBER, Vivek. Postcolonial theory and the specter of capital. London: Verso, 2013.

CONNEL, Raewyn. A iminente revolução na teoria social. Revista Brasileira de Ciências Sociais, [S.l.], v. 27, n. 80, p. 9-20, 2012.

CROUCHER, Sheila. Privileged Mobility in an Age of Globality. Societies, [S.l.], v. 2, p. 1-13, 2012.

DIRLIK, Arif. The postcolonial aura: Third World criticism in the age of global capitalism. Boulder: Westview Press, 1997.

GHOSH, Amitav. The Diaspora in Indian culture. Public Culture, [S.l.], v. 2, n. 1, p. 73-78, 1989.

GROSSI, Miriam. Duas Germaines e Uma Denise: as alunas de Mauss. In: MOTTA, Antonio; CAVIGNAC, Julie (Org.). Antropologia francesa no século XX. Recife: Massangana, 2006. p. 239-256.

GROSSI, Miriam; LAGO, Claudia (Org.). Trabalho de campo e subjetividade. Florianópolis: PPGAS-UFSC, 1992.

GUDAVARTHY, Ajay. Brahmanism, liberalism and post-colonial theory. Economic and Political Weekly, [S.l.], v. 51, n. 24, p. 15-17, 2016.

GUHA, Ramachandra. The ones who stayed behind. In: ASSAYAG, Jackie; BÉNÉİ, Véronique (Org.). At home in diaspora: South Asian scholars and the West. Bloomington: Indiana University Press, 2003. p. 163-177.

HALL, Stuart. Identités et cultures 2: politiques des différences. Paris: Editions Amsterdam, 2013. 
HALL, Stuart. Old and new identities, old and new ethnicities. In: KING, Anthony (Org.). Culture, globalization and the world-system: contemporary conditions for the representation of identity. Minneapolis: University of Minnesota Press, 1997. p. 41-68.

HARAWAY, Donna. Saberes localizados: a questão da ciência para o feminismo e o privilégio da perspectiva parcial. Cadernos Pagu, [S.l.], v. 5, p. 7-42, 1995.

KAVIRAJ, Sudipta. On the advantages of being a barbarian. In: ASSAYAG, Jackie; BÉNÉİ, Véronique (Org.). At home in diaspora: South Asian scholars and the West. Bloomington: Indiana University Press, 2003. p. 148-162.

PEIRANO, Mariza. The Anthropology of Anthropology: the Brazilian case. 1981. Tese (Doutorado em Antropologia Social) - Harvard University, Cambridge, 1981 .

RAO, Rahul. Postcolonialism. In: FREEDEN, Michael; STEARD, Marc (Org.). The Oxford Handbook of Political Ideologies. Oxford: Oxford University Press, 2013. p. 271-289.

RIBEIRO, Gustavo Lins. World Anthropologies: anthropological cosmopolitanisms and cosmopolitics. Annual Review of Anthropology, [S.l.], v. 43, p. 483-498, 2014.

RIBEIRO, Gustavo Lins; ESCOBAR, Arturo (Org.). World Anthropologies: disciplinary transformations within systems of power. Oxford: Berg, 2006.

SPIVAK, Gayatri Chakravorty. Postcolonial theory and the specter of capital. Cambridge Review of International Affairs, [S.l.], v. 27, n. 1, 184-198, 2014.

SPIVAK, Gayatri. Who claims alterity? In: KRUGER, Barbara; MARIANI, Phil (Org.). Remaking History. Seattle: Bay Press, 1992. p. 269-292.

SRIVASTAVA, Sanjay. Modernity and post-coloniality. The metropolis as metaphor. Economic and Political Weekly, [S.l.], v. 31, n. 7, p. 403-412, 1996.

SUBRAHMANYAM, Sanjay. Leçons indiennes: itinéraires d'un historien (Delhi-Lisbonne-Paris-Los Angeles). Paris: Alma, éditeur, 2015.

TAGORE, Rabindranath. Rabindranath Tagore Omnibus II. New Delhi: Rupa \& Co, 2003.

TÖLÖLYAN, Khachig. Restoring the logic of sedentary to diaspora studies. In: ANTEBY-YEMINI, Lisa; BERTHOMIÈRE, William; SCHEFFER, Gabriel (Org.). Les diasporas: 2000 ans d'histoire. Rennes: Presses Universitaires de Rennes, 2005. p. 137-148. 
VAN BOEKEL, Marli. How privileged are 'privileged migrants'? An ethnographic case study of excellent foreign students studying at the National University of Singapore. 2013. Dissertação (Master em Management of Cultural Diversity) - Tilburg University, Tilburg, 2013.

VAN DER VEER, Peter; LEHMANN, Hartmut. Nation and religion: perspectives on Europe and Asia. Princeton: Princeton University Press, 1999.

WEBER, Max. A objetividade do conhecimento nas ciências sociais. São Paulo: Ática, 2006.

Recebido em 04/09/2017

Aceito em 05/10/2017 